\title{
Об использовании хроматографических терминов и понятий в англоязычных статьях по теме «Хроматография»
}

\author{
® 2019 Ванюхина М.А., Берёзкин В.Г. \\ Институт нефтехимического синтеза им. А.В. Топчиева РАН (ИНХС РАН), Россия, Москва
}

Поступила в редакцию 12.12.2019 г.

DOI: $10.17308 /$ sorpchrom.2020.20/2387

Хроматография активно развивается и используется для научных исследований уже более 100 лет. Тема хроматографической лексики имеет важное значение для различных разделов химии (особенно для физической и аналитической химии). Хроматография применяется во всем мире в научных исследованиях, в различных отраслях промышленности, в медицине, в фармацевтике, в криминалистике, для контроля окружающей среды и т.д. Универсальным языком межкультурной коммуникации, языком мировых научных публикаций, языком научного мира (т.н. «лингва франка») является английский. С целью анализа хроматографической языковой картины мира в статье была изучена частота использования основных англоязычных хроматографических терминов и понятий, используемых в англоязычных статьях, по теме «хроматография». Метод статистической обработки основан на подсчете количества терминов, используемых в статьях. Была проведена обработка статистических данных, взятых из международной реферативной базы данных «Web of Science Core Collection». Было дано описание хроматографической терминосистемы и ядерных терминов. Терминологическая система - это упорядоченное множество терминов с отношениями внутри системы. Любая терминосистема является основой для составления словарей или для работы переводчика. Была предложена научная картина мира, которая отражает ядро языкового сознания хроматографиста как ученого и исследователя. Смысл слова или термина создает семантическую сеть, которая является основой языкового сознания. Научная картина мира хроматографиста отражена в хроматографическом словаре. Другими словами, исследуемые термины и понятия позволяют виртуально «сконструировать» научную картину мира хроматографиста, которая отражает (ментальный) лексикон и языковое сознание хроматографиста. Ядерная (центральная) и периферическая лексика науки позволяет хроматографисту оперировать необходимыми терминами и понятиями. Описание лексики демонстрирует структуру науки хроматографии. Научная картина мира выглядит, как сложная многослойная модель. Ядро лингвистического сознания отражает объективный опыт хроматографистов, тогда как периферические термины касаются субъективного научного опыта. Термины общего языка - «mass», «analysis», «determination», например, отражают широкие философские аспекты научной деятельности хроматографиста. Нами был рассмотрен также такой аспект, как частота упоминания основных разделов хроматографии в статьях по ГХ, ЖХ, ТСХ. Данное исследование представляет интерес как для перевода, так и для чтения и анализа научной литературы в области хроматографии.

Ключевые слова: хроматография, тонкослойная хроматография, ТСХ, газовая хроматография, ГХ, жидкостная хроматография, ЖХ, хроматографические термины, английский язык.

\section{Введение}

Хроматография развивается и активно используется в научных исследованиях уже более 100 лет, а хроматографические явления реализуются в природе уже многие сотни лет. Как особое самостоятельное явление хроматография была открыта 
впервые российским ученым М.С.Цветом и реализована им в качестве аналитического метода в научных исследованиях, например, в ботанике $[1,2]$.

В литературе опубликовано много определений хроматографии. Этот вопрос носит общий характер, и он широко обсуждается. Так, согласно определениям Научного Совета по хроматографии РАН, хроматография - это наука, которая отражает межмолекулярные взаимодействия и перенос молекул или частиц в системе несмешивающихся и движущихся относительно друг друга фаз. Там же есть определение хроматографии как метода: хроматография - это метод разделения смесей веществ или частиц, основанный на различии в скоростях их перемещения в системе несмешивающихся и движущихся относительно друг друга фаз [2, 3].

По нашему мнению, целесообразно рассматривать хроматографию как особую область, являющуюся неотъемлемой частью двух важных областей наук: физической и аналитической химии $[2,4]$.

Что касается физической основы данного термина, то согласно [5], «хроматография - область науки, изучающая движение вещества (или группы веществ) в потоке одной (или нескольких) фазы, движущейся относительно другой фазы (или нескольких других фаз)».

Хроматография активно применяется в научных исследованиях, в различных отраслях промышленности, в медицине, в фармацевтике, в криминалистике, для контроля окружающей среды.

В нашей работе производится оценка языковой картины мира хроматографиста на основании анализа статей по теме «хроматография». Дается характеристика ядра языкового сознания хроматографиста. Согласно определению ИЮПАК, хроматография - это физико-химический метод разделения, в котором разделяемые компоненты в процессе разделения распределены между двумя фазами: одна из которых - неподвижна, а вторая (подвижная фаза) - движется относительно первой. (Chromatography is a physical method of separation in which the components to be separated are distributed between two phases, one of which is stationary (stationary phase) while the other (the mobile phase) moves in a definite direction) [6]. Тема хроматографической лексики важна для физической химии и отражает основные понятия науки.

Методические основы и материалы нашего исследования. Английский язык как основной язык научного общения (лингва франка). Термины «ядро языкового сознания», «языковая картина мира», «языковая личность», «билингвизм» и другие.

В данной статье проведена статистическая частоты употребления лексем (терминов и понятий) по теме «хроматография» по данным реферативной базы данных журнальных статей (и абстрактов научных конференций) «Web of Science Core Collection» (составная часть «ISI Web of Knowledge») по Интернет-запросу «chromatography» (с уточнением/конкретизацией при поиске «chemistry analytical») за период 1975-2019 гг. (185792 записей совпали с запросом «сhromatography» из 65719865, согласно «Web of Science Core Collection» [7]).

Лексема (от греч. «lexis» - «слово, выражение») - единица словарного состава языка в совокупности его грамматических форм и конкретных смысловых вариаций[8].

O базе данных «ISI Web of Knowledge» [7] известно, что это интегрированная Интернет-платформа компании «Clarivate Analytics» (ранеe она принадлежала «Thomson Reuters»). В состав «ISI Web of Knowledge» входят мультидисциплинарная аналитическая реферативная база данных «Web of Science Core Collection» (доступ к этой платформе ограничен). В базе данных «Web of Science Core Collection» нами было проанализировано содержание абстрактов и названий большого количества журналов по теме «хроматография» (см. таблицу 1). Недавно в нашем Институте 
(ИНХС РАН) появился доступ к большим ресурсам платформы «ISI Web of Knowledge», но на момент написания статьи у нас не было сведений об этом, и нам была доступна только «Web of Science Core Collection». К тому же, нам кажется, что использованной в данной работе выборки достаточно для анализа. («Clarivate Analytics» - это независимая американская компания, основанная в 2016 году, управляющая базами данных (её работа финансируется на основе электронной подписки к её услугам, чем и ограничивается доступ к ней). До 2016 года интеллектуальная собственность компании принадлежала «Thomson Reuters»).

Таблица 1. Список англоязычных журналов (первые 35), статьи в которых были проанализированы в этой работе (они расположены по убыванию количества статей по теме «хроматография») (с 1975-2019 гг.)

\begin{tabular}{|c|c|}
\hline Название журнала & $\begin{array}{c}\text { Количество исследован- } \\
\text { ных статей по теме } \\
\text { «хроматография»* }\end{array}$ \\
\hline 1. JOURNAL OF CHROMATOGRAPHY A & 3351 \\
\hline 2. $\quad$ ANALYTICAL CHEMISTRY & 1077 \\
\hline 3. JOURNAL OF SEPARATION SCIENCE & 993 \\
\hline 4. $\quad$ ANALYTICA CHIMICA ACTA & 816 \\
\hline 5. TALANTA & 681 \\
\hline 6. ANALYTICAL AND BIOANALYTICAL CHEMISTRY & 606 \\
\hline 7. CHROMATOGRAPHIA & 574 \\
\hline 8. $\quad$ JOURNAL OF CHROMATOGRAPHY B & 537 \\
\hline $\begin{array}{l}\text { 9. ANALYTICAL TECHNOLOGIES IN THE BIOMEDICAL } \\
\text { AND LIFE SCIENCES }\end{array}$ & 400 \\
\hline 10. ANALYTICAL METHODS & 323 \\
\hline $\begin{array}{l}\text { 11. JOURNAL OF PHARMACEUTICAL AND BIOMEDICAL } \\
\text { ANALYSIS }\end{array}$ & 267 \\
\hline 12. ANALYST & 265 \\
\hline $\begin{array}{l}\text { 13. JOURNAL OF LIQUID CHROMATOGRAPHY RELATED } \\
\text { TECHNOLOGIES }\end{array}$ & 246 \\
\hline 14. RAPID COMMUNICATIONS IN MASS SPECTROMETRY & 229 \\
\hline 15. CHINESE JOURNAL OF ANALYTICAL CHEMISTRY & 226 \\
\hline 16. JOURNAL OF CHROMATOGRAPHY & 181 \\
\hline 17. MICROCHEMICAL JOURNAL & 126 \\
\hline 18. JOURNAL OF AOAC INTERNATIONAL & 124 \\
\hline 19. ANALYTICAL LETTERS & 122 \\
\hline 20. JOURNAL OF CHROMATOGRAPHIC SCIENCE & 117 \\
\hline 21. TRAC TRENDS IN ANALYTICAL CHEMISTRY & 111 \\
\hline 22. ANALYTICAL BIOCHEMISTRY & 109 \\
\hline $\begin{array}{l}\text { 23. INTERNATIONAL JOURNAL OF ENVIRONMENTAL } \\
\text { ANALYTICAL CHEMISTRY }\end{array}$ & 106 \\
\hline 24. ANALYTICAL SCIENCES & 100 \\
\hline 25. MICROCHIMICA ACTA & 97 \\
\hline 26. JOURNAL OF MICROCOLUMN SEPARATIONS & 95 \\
\hline 27. JOURNAL OF ANALYTICAL CHEMISTRY & 91 \\
\hline $\begin{array}{l}\text { 28. JOURNAL OF THE AMERICAN SOCIETY FOR MASS } \\
\text { SPECTROMETRY }\end{array}$ & 84 \\
\hline $\begin{array}{l}\text { 29. HRC JOURNAL OF HIGH RESOLUTION CHROMATO- } \\
\text { GRAPHY }\end{array}$ & 68 \\
\hline 30. CHINESE JOURNAL OF CHROMATOGRAPHY & 65 \\
\hline 31. JOURNAL OF CHROMATOGRAPHY B & 60 \\
\hline
\end{tabular}




\begin{tabular}{|l|c|}
\hline \multicolumn{1}{|c|}{ Название журнала } & $\begin{array}{c}\text { Количество исследован- } \\
\text { ных статей по теме } \\
\text { «хроматография»* }\end{array}$ \\
\hline $\begin{array}{l}\text { 32. JPC JOURNAL OF PLANAR CHROMATOGRAPHY MOD- } \\
\text { ERN TLC }\end{array}$ & 59 \\
\hline 33. LC GC NORTH AMERICA & 65 \\
\hline 34. JOURNAL OF LIQUID CHROMATOGRAPHY & 55 \\
\hline 35. PHYTOCHEMICAL ANALYSIS & 50 \\
\hline
\end{tabular}

* Журналы расположены в порядке убывания количества статей, проанализированных нами в базе данных «ISI Web of Knowledge»

Наиболее важной характеристикой употребляемости научной лексики (термина и/или понятия) является частота их использования (употребления). Высокочастотные или часто употребляемые термины формируют ядро языкового сознания и языковую картину мира ученого (см. работы [9-12]).

Ядро языкового сознания - это единицы семантической сети, которые имеют наибольшее число связей с другими единицами данной семантической сети [по (А.А. Залевская, 1999) в [9-12]]. Семантика - 1) всё содержание, информация, передаваемое языком или какой-либо его единицей (словом, грамматической формой слова, словосочетанием, предложением); 2) раздел языкознания, изучающий это содержание, информацию [8].

Стоит отметить, нами здесь не анализируются только так называемые ассоциативные связи, в силу того, что это не художественная (как, например, в работах по лингвистике Н.В.Уфимцевой с соавт. [9-12]), а научно-техническая лексика, и выявленные связи, на наш взгляд, скорее логические, нежели исключительно ассоциативные.

Особенностью нашего подхода является то, что выборка анализируемых статей учитывает языковое поле, как авторов первичного текста, в том числе англоговорящих (имеются ввиду «native speakers»- американцы, британцы, австралийцы и т.д.), так и язык вторичных текстов, порождённых переводчиками-билингвами («non-native speakers»), которых можно назвать «языковыми личностями».

Языковое поле в общих понятиях можно трактовать как лексикосемантическую систему, объединяющую лексемы или лексико-семантические варианты в различных смежных связях $[13,14]$. Языковая личность - это любой носитель того или иного языка, охарактеризованный на основе анализа произведенных им текстов с точки зрения использования в этих тестах системных средств данного языка для отражения видения им окружающей действительности (картины мира) и для достижения определенных целей в этом мире [15].

Билингвизм (двуязычие) (в узком смысле) означает более или менее свободное владение двумя языками; (в широком смысле) - относительное владение вторым языком, умение в том или ином объёме пользоваться им в определённых сферах общения. Относительно контекста формирования билингвизма (по классификации из лекций Т.В.Черниговской) выделяют т.н. «естественный билингвизм» («natural bilingualism», «primary bilingualism») и т.н. «искусственный билингвизм» («artificial bilingualism», «secondary bilingualism») [16].

Иначе говоря, билингвы - это люди, имеющие два родных языка, а также преподаватели иностранных языков и переводчики, профессионально владеющие иными языками. У билингвов одновременно сосуществуют две языковые картины мира, у специалистов по иностранным языкам вторичная языковая картина мира накладывается на первичную, заданную родным языком [17]. 
Согласно классификации Л.Хоффмана, профессиональная коммуникация может осуществляться внутри специальности («fachinterne»- (здесь) хроматографистов с хроматографистами); между представителями разных отраслей знания (межотраслевая - «interfachliche» - хроматографистов, например, с фармацевтами) и за пределами специальности («fachexterne» - общение экспертов и неспециалистами) [18].

Универсальным языком межкультурной коммуникации, языком научного мира, лингва франка, языком мировых научных публикаций, понятный большинству ученых разных стран является английский [6]. Лингва франка (от итал. «lingua franca» - «франкский язык») - язык, используемый как средство межэтнического общения в определенной сфере деятельности между людьми, родными языками которых являются другие языки [8].

Перевод - это способ осуществления межкультурной коммуникации, причем такая коммуникация является необходимым промежуточным этапом, опосредующим межкультурное общение автора и читателя. Переводчик же является реципиентом (получателем) инокультурного текста и автором нового (т.е. вторичного) текста [19]. Другими словами, переводчик - это посредник в передаче текста реципиентучитателю, он же отвечает за адекватность перевода и/или его эквивалентность [20].

Понятие картины мира является междисциплинарным. Оно было осмыслено в рамках точных наук, философии и лингвистики. Языковая картина мира отражает представление реального мира в системе понятий и категорий языка [9-12].

В данном исследования нами было проанализировано около 180 англоязычных терминов и понятий - узких хроматографических и общенаучных, которые были расположены в порядке убывания частоты их употребления. Их список, несомненно, можно продолжить. Далее нами была построена схема, отражающая языковую картину мира хроматографиста [10-12].

В статье нами исследуется частота, а не частотность, так как первая отражает «чистую» количественную характеристику, тогда как частотность демонстрирует относительные данные, что имеет ценность скорее для составления частотных словарей [21]. Частота - это абсолютное число (в отличии от относительного показателя - частотности), показывающее, сколько раз каждая лексическая единица (лексема, слово, словоформа) встретилась в данной выборке [21].

Авторами данной статьи рассматривается, в основном, самые частотные лексемы, имеющие полные переводческие эквиваленты или кальки (от франц. «calques») в других европейских языках, т.е. не лакунарные.

Термин «переводческий эквивалент» встречается, например, в работе [22]. Калька - это поморфемный или пословный перевод иноязычного слова [8].

Лакуны же - это «пробелы, «белые пятна» на семантической карте языка, текста и культуры, являющиеся способами существования национального сознания» $[23,24]$. В других источниках лакуны («lacunas» или «gaps») часто называют безэквивалентной лексикой (см. работы [24-26]). Так называемые «элиминированные» или «заполненные» лексические лакуны можно (в общих словах) называть «новыми терминами» [27], или более научно «техническими неологизмами» («словами, не зафиксированными пока в словарях») [28]. Элиминирование (заполнение) - это объяснение, расшифровка нового термина, например, посредством переводческого комментария (по [24]). Лакуны характеризуются крайне низкой частотой и частотностью употребления, и небольшим количеством авторов, употребивших их, новизну (например, это новое научное достижение). Поэтому нами они в статье не рассматриваются.

Примером типичной лакуны в хроматографической литературе является словосочетание «dwell volume», которое встречается в статьях по градиентной обраще- 
но-фазовой хроматографии («gradient reversed-phase chromatography») приблизительно 50 раз. Адекватного переводческого эквивалента в русскоязычных источниках нами не было найдено, понятие не зафиксировано в специальных отечественных словарях, а найденные в поиске в сети Интернет варианты перевода вызывают у авторов данной статьи сомнение, хотя термин встречается, например, в книге [29].

Что касается анализа других литературных источников, кроме журнальных статей, то, по нашему мнению, статистический анализ частоты терминов и понятий в книгах не имеет в данном случае значимых показателей по сравнению с анализом массива данных статей в большой (даже колоссальной) выборке «Web of Science Core Collection», но, возможно, они будут проанализированы в дальнейших исследованиях.

Одновременно с этим (и это имеет принципиальное значение) лексический состав книг и словарей содержит базовую академическую лексику в той или иной области науки и даёт возможность для выбора, поиска тех или иных лексических единиц - понятий и терминов (которые мы в дальнейшем исследуем) и формирования критериев выборки.

Термины и понятия хроматографии как науки и метода. Терминологическое ядро языкового сознания хроматографиста.

Термины и понятия для данной работы были взяты нами из литературы (монографий по хроматографии, а также авторского словаря) [30-35]. Критерием их отбора стала частота использования терминов в этих источниках в заголовках и указателях терминов. Что касается лексико-грамматических аспектов данного исследования, для анализа рассматривались имена существительные, имена прилагательные, герундии и причастия (например, «quenching» - «гашение»). В статье не рассматривались общеупотребительные глаголы (например, «to include», «to fix», и др.), а также наречия (например, «simultaneously» или «carefully») и другие части речи, имеющие важное значение в научной литературе, ввиду их очень общего употребления. Патенты и формулы изобретений также, несомненно, представляют общий интерес в плане лексического анализа, но мы их в работе не рассматриваем, так как их содержание не вполне развернуто. Фармакопеи (специальная область лексики, источник терминов, применимых в медицине и смежных науках и отраслях) являются также источником, подтверждающим общую употребляемость терминов и понятий, однако, в данной статье они нами не учитываются.

В этой статье авторами рассматривается частота употребления не только простых, но и многокомпонентных [28] терминов (состоящих из более чем одного слова) или «терминов-словосочетаний», которые находятся, как правило, в так называемой атрибутивной [36] (т.е. определительной) - например, «separation ratio», «response time», «stationary phase», «ionization detector» - или равноправной (например, «simple and sensitive» (про метод)) связи друг с другом.

Хроматографические термины (таблица 2, колонка слева) и общенаучные термины и понятия (таблица 2 , колонка справа) расположены нами по убыванию количества употребления при анализе массива данных, учитывающих суммарно лексику статей в базе данных «Web of Science Core Collection» в заголовке и аннотации (интегративная база данных научных статей «ISI Web of Science» содержит данные, включающие оглавления, аннотации, библиографическую информацию).

В данной статье нами также рассмотрены лексемы общенаучного характера, без которых невозможно описать научное открытие, опыт или научной теорию. В одной из наших работ [36], например, уже был рассмотрен аспект частоты использования некоторых терминов общенаучной лексики в контексте научного перевода. 
Таблица 2. Частота употребляемости терминов и понятий по теме «Хроматография» в статьях на английском языке по данным «Web of Science Core Collection» или терминосистема (термины и понятия расположены в порядке убывания частоты их употребления; цифра слева от термина показывает частоту его встречаемости в данной выборке).

\begin{tabular}{|c|c|}
\hline Характерные хроматографические термины & Общенаучные термины и понятия \\
\hline 82283 Phase & 125670 Liquid \\
\hline 81000 Sample & 99020 Method \\
\hline 77219 Detection & 84300 Mass \\
\hline 61584 Separation & 81000 Analysis \\
\hline 55000 Column & 72369 Determination \\
\hline 50500 Sample mass & 52000 Range \\
\hline 49066 Extraction & $46770 \mathrm{Gas}$ \\
\hline 39000 HPLC & 46360 Compound \\
\hline 30650 Capillary & 46250 Concentration \\
\hline 26700 Mobile & 32350 System \\
\hline 26000 Mobile phase & 27936 Extract \\
\hline 25030 Coupled & 27100 Application \\
\hline 23720 Reversed-phase & 26700 Mobile \\
\hline 23000 Sensitive & 26620 Technique \\
\hline 19500 Retention & 25700 Effect \\
\hline 18930 Stationary & 22000 Simple \\
\hline 18900 Peak & 21499 Matrix \\
\hline 18800 Resolution & 21000 Rapid \\
\hline 18000 Stationary phase & 19610 Mixture \\
\hline 18000 Preparation & 18540 Process \\
\hline 17200 Development & 15730 Component \\
\hline 15670 Injection & 15300 Factor \\
\hline 15500 Elution & 14700 Coefficient \\
\hline 15350 Surface & 14500 Efficiency \\
\hline 13100 Derivatization & 13200 Detector \\
\hline 12630 Gradient & 12940 Volume \\
\hline 11500 Flow rate & 11000 Fast \\
\hline 11000 Layer & 10760 Pressure \\
\hline 8500 Zone & 10100 Size \\
\hline 8140 Packing & 9700 Spectrum \\
\hline 7800 Reproducibility & 7960 Set \\
\hline 7560 Packed & 7657 Conventional \\
\hline 7000 Simple and Sensitive & 7650 Tool \\
\hline 6800 Support & 7540 Substance \\
\hline 6700 Volatile & 7520 Advantage \\
\hline 6200 Repeatability & 6900 Capacity \\
\hline 6200 Plate & 6730 Volatile \\
\hline 5800 Silica gel & 6300 Optimum \\
\hline 5600 Sorbent & 6100 Weight \\
\hline 5120 Automated & 5700 Isomer \\
\hline 4900 Immobilized & 5349 Traditional \\
\hline 4800 Separation ratio & 5200 Research \\
\hline 4780 Exclusion & 5080 Maximum \\
\hline 4500 Peak area & 4930 Solute \\
\hline 4300 Liquid sorbent & 3600 Additive \\
\hline 4000 Solid sorbent & 3600 Noise \\
\hline 3850 Impurity & 3560 Release \\
\hline 3760 Response time & 3500 Theoretical \\
\hline 3704 Probe & 3200 Practical \\
\hline 3500 Migration & 2920 Discovery \\
\hline 3400 Adsorbent & 2900 Equation \\
\hline 3300 TLC* & 2600 Diameter \\
\hline
\end{tabular}




\begin{tabular}{|c|c|}
\hline Характерные хроматографические термины & Общенаучные термины и понятия \\
\hline 3300 Base line & 2490 Consumption \\
\hline 3200 Fused & 2430 Dispersion \\
\hline 2800 Thin-layer chromatography & 2300 Trace amounts \\
\hline 2800 Wall & 2270 Calculation \\
\hline 2750 Band & 2230 Criterion \\
\hline 2662 Pore & 2150 Limitation \\
\hline 2600 Noise ratio & 2140 Fingerprint \\
\hline 2500 Adjusted & 2100 Dependence \\
\hline 2489 Glass & 2000 Trends \\
\hline 2380 Dye & 1970 Minimum \\
\hline 2290 Ionization detector & 1850 Medicinal \\
\hline 1960 Column length & 1700 Equivalent \\
\hline 1900 Vapor & 1535 Isotherm \\
\hline 1600 Tubular & 1150 Width \\
\hline 1530 Hyphenated & 1050 Evaporate \\
\hline 1500 Chromatogram & 820 Apparatus \\
\hline 1400 Overlap & 700 Approximate \\
\hline 1315 Aliquot & 698 Disadvantage \\
\hline 1300 Saturated & 360 Steam \\
\hline 1300 Planar & 350 Radius \\
\hline 1190 Theoretical Plate & 326 Humidity \\
\hline 980 Vapor phase & 39 Rapidness \\
\hline 970 Carrier gas & 27 Semiautomatic \\
\hline 960 Chamber & 13 Fastness \\
\hline 940 Unsaturated & \\
\hline 888 Quenching & \\
\hline 863 Adsorption layer & \\
\hline 820 Peak width & \\
\hline 811 Supply & \\
\hline 670 Impregnated & \\
\hline 590 Overload & \\
\hline 514 Modifying agent & \\
\hline 430 Uncoated & \\
\hline 410 Inorganic salt & \\
\hline 390 Inlet pressure & \\
\hline 350 Asymmetry & \\
\hline 290 Immersed & \\
\hline 265 Sandwich & \\
\hline 240 Molecular sieve & \\
\hline 238 Horizontal & \\
\hline 230 Vertical & \\
\hline 220 Inert gas & \\
\hline 190 Band width & \\
\hline 134 Retardation & \\
\hline 112 Ascending & \\
\hline 109 Start line & \\
\hline 105 Sorption layer & \\
\hline 70 Descending & \\
\hline 57 Chromatographer & \\
\hline 33 Involatile & \\
\hline
\end{tabular}

*«TLC» и «thin-layer chromatography» - один и тот же термин, но первый из упомянутых является аббревиатурой. При количественной оценке использовалась сумма упоминаний обеих форм словосочетания в поиске

Так как в статье говорится о понятийном ядре языкового сознания ученогохроматографиста (которое формируется из понятий), то, по-видимому, следует дать 
некоторые определения. Понятие (концепт) - мысль, отражающая в обобщенной форме предметы и явления действительности посредством фиксации их свойств и отношений, имеющих общие и специфические признаки, соотнесенные с классами предметов и явлений [8]. Например, примерами понятий в данной статье являются слова «practical», «theoretical», «system», «size», «trends», «discovery» и т.д. Разделение понятий и терминов носит несколько условный пограничный характер. В лингвистическом словаре [8] есть также определение слова «термин». Термин (от лат «terminus» - граница, предел) - слово или словосочетание, обозначающее понятие специальной области знаний или деятельности. Термин входит в общую лексическую систему языка, но лишь через посредство конкретной терминологической системы (терминологии). Термины могут заимствоваться из другого языка (понятие «калька»- см. выше) [8]. Согласно другому определению, термин - это эмоционально-нейтральное слово (словосочетание), передающее название точно определенного понятия, относящегося к той или иной области науки и техники [38]. В левой колонке таблицы 2 располагаются термины, условно формирующие терминологическое ядро языкового сознания хроматографиста с ядерными (ключевыми) и периферическими (менее частотными) терминами.

В данной статье нами рассматриваются данные по приблизительно 186000 статьям по теме «chromatography» с уточнением (конкретизацией) при поиске «сhemistry analytical». Они расположены в схеме, демонстрирующей ядро языкового сознания хроматографиста на рис. 2 от центра (ядра языкового сознания) к границе окружности (периферическому слою терминов) по мере убывания частоты их употребления.

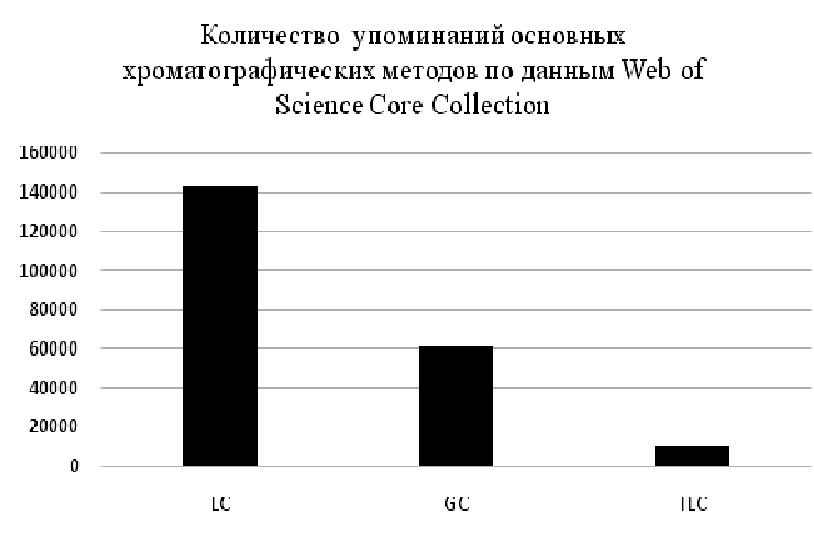

Рис. 1. Частота упоминаний хроматографических методов в базе данных «Web of Science Core Collection» (за период 1975-2019).

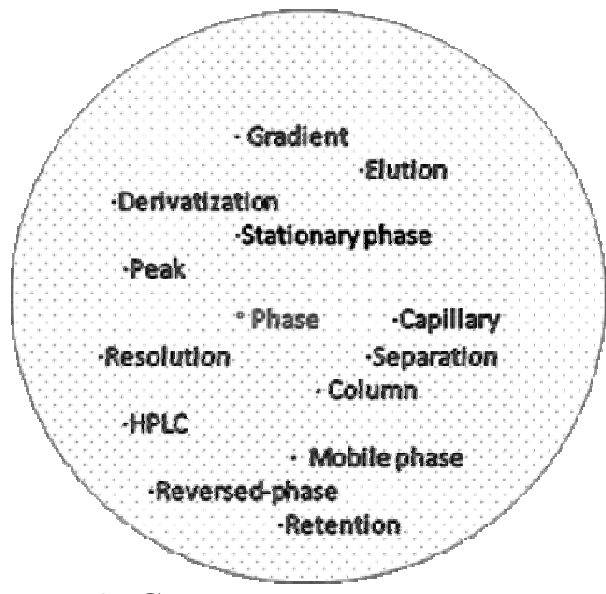

Рис. 2. Схематичное ядро языкового сознания хроматографиста (часто употребляемые термины расположены в порядке убывания от центра; более подробные данные приведены в табл. 1).

Языковая картина мира хроматографиста

Как видно из табл. 2, самым частотным словом оказалось «phase», далее по количеству упоминаний следуют «sample», «detection», «separation», «column». Это условное ядро языкового сознания хроматографиста.

Популярность трёх основных хроматографических методов отражается в схеме на рис. 1. Из этой диаграммы следует, что по частоте употребления в статьях доминирует жидкостная хроматография. Далее следует газовая и тонкослойная хрома- 
тография. Последний из упомянутых методов - тонкослойная хроматография, хотя и имеет самую низкую частоту употребления в статьях (около 10000 упоминаний за 44 года), он весьма актуален и популярен, благодаря своей простоте и, несомненно, высокой эффективности (см., например, авторскую работу по основным направлениям использования тонкослойной хроматографии [37]).

Согласно [40], науке необходимы особые средства деятельности - специальный язык (эмпирический и теоретический). Таким образом, наличие ядерной и периферической лексики (терминов и понятий) в анализируемой условной выборке научных статей по теме «хроматография» подчеркивает тот факт, что хроматография и метод, и научная дисциплина. На рис. 2 схематично отражено ядро языкового сознания хроматографиста по данным табл. 2 (колонка слева) и его языковая картина мира.

Самый частотный термин «рhase» расположен в центре, а менее частотные от центра к периферии по всем диаметрам. Данный рисунок схематичен и, разумеется, не отражает количество всех терминов, частоту которых можно подробно изучить в вышеупомянутой табл. 2. Термины «phase», «layer», «separation», «detection», и т.п., имеющие частое употребление, являются ядерными и принципиально значимыми для языкового сознания ученых-хроматографистов. Согласно [36], терминологическая система («терминосистема») - упорядоченное множество терминов с отношениями между ними. Любая терминосистема является основой для составления словарей по специальности (см. словарь [34]).

Ядро языкового сознания суммирует объективный опыт ученых, а околоядерные (периферические) термины (т.н. «оболочка») - более субъективный научный опыт. Ядерные понятия и термины общего языка («liquid», «method», «mass», «analysis», «determination») отражают более широкие, даже философские аспекты научной деятельности хроматографиста, а менее частотные периферические термины и понятия являются концептами метода.

\section{Заключение}

В работе была построена терминосистема и схема, отражающая языковое ядро хроматографиста и языковую картину мира.

Данная работа посредством статистической обработки данных и их лингвистического анализа подтверждает, что хроматография - это развитая отрасль знания и наука, имеющая кроме теоретических и практических основ структурированный понятийный аппарат (с типичной ядерной и периферической научной лексикой), языковое ядро терминов (с высокочастотными и менее частотными терминами) и околоядерный (периферический) слой важных хроматографических терминов и понятий.

Термины и понятия из этой области формируют научную картину мира ученого-хроматографиста, имеющую вид многослойной модели, и отражающую ментальный лексикон и языковое сознание хроматографиста. Специалист, обладающий умениями и навыками в области хроматографии, является носителем ядерной и околоядерной научной лексики, может свободно и грамотно оперировать всеми терминами и понятиями, что структурирует его знания и дает опыт (и возможности) для логичного описания закономерностей, научных достижений и экспериментов. Без знания терминологической лексики овладение наукой или специальностью невозможно.

Понятия, исследованные в работе, могут формировать определенные понятийные категории и формируют понятийное ядро, которое отражает общность хроматографии с другими науками. 
Стоит отметить, что нами не были ранее выявлены в научной литературе работ аналогичного характера. Закономерности, которые мы пытались установить в этой работе, представляют, на наш взгляд, интерес как для хроматографистов, химиков-аналитиков, так и для научных и технических переводчиков, лингвистов, филологов.

Интерес к лексическому составу статей по теме «хроматография» отражает, прежде всего, научную картину мира хроматографиста, а также важность лингвистической составляющей - основы лексики, имеющей также важное значение, например, для составления словарей, при переводе, чтении и анализе научной литературы в сфере хроматографии.

\section{Статья выполнена в рамках Государственного задания ИНХС РАН}

\section{Список литературы}

1. Цвет М.С. Избранные труды / под. ред. Ю.А. Золотова. М. Наука. 2013. 679 с.

2. Берёзкин В.Г. Введение в хроматографию. М. Научный Мир. 2016. 96 с.

3. Хроматография: Основные понятия. Терминология. РАН. Ком. науч. терминологии в обл. фундам. наук, Науч. совет по хроматографии, Сборник науч.-норматив. терминологии; Вып. 114. М. 1977. страницы

4. Берёзкин В.Г. // Журнал аналитической химии. 2001. Т. 56. № 8. С. 871.

5. Берёзкин В.Г., Гавричев В.С., Коломиец Л.Н., Королев А.А. и др. Газовая хроматография в нефтехимии. М.: Наука, 1975. $271 \mathrm{c}$.

6. PAC. (Nomenclature for chromatography (IUPAC Recommendations)). 1993. 65. pp. 819,823 .

7. Web of Science Core Collection, Режим доступа: [https://apps.webofknowledge.com/ WOS_GeneralSearch_input.do?product=WOS \&search_mode=GeneralSearch\&SID=F6Jeoan1 DdgmtJlOcGE\&preferencesSaved=] (дата обращения 20.12.19)

8. Лингвистический энциклопедический словарь. Под ред. В.Н. Ярцева. М. Советская энциклопедия. 1990. 685 с.

9. Уфимцева Н.В. // Язык в пространстве речевых культур (К 80-летию Е.В. Гольдина). Москва-Саратов. Наука образования. 2015. C. 335-342.

10.Залевская А.А. Введение в психолингвистику. М. Российский государственный гуманитарный ун-т. 1999. 382 с.

11.Уфимцева Н.В. // Язык и метод: Русский язык в лингвистических исследованиях XXI века, т.2: Лингвистический анализ на грани методологического срыва. 2015. С. 249-256.

12.Уфимцева Н.В., Балясникова О.В. // Вестник ВолГУ. Серия 2. Языкознание. 2019. T. 18. № 1. C. 6-22.

13.Кронгауз М.А. Семантика. М. Академия. 2005. $352 \mathrm{c.}$

14.Васильев Л.М. // Вопросы языкознания. 1971. № 3. С. 105-113.

15.Русский язык: энциклопедия / Под ред. Ю.Н. Караулов. М. Большая рос. энцикл. Дрофа. 1997. 704 c.

16. Hornby P.A. et al. Bilingualism - Psychological, Social and Educational Implications. New York, San Francisco. London. Academic Press Inc. 1977. 167 р. (в лекциях Т.В. Черниговской в рамках онлайн-курса СПбГУ «Психолингвистика», онлайн платформа «Открытое образование». 2017. Режим доступа: [https://openedu.ru/course/spbu/ PSYLING/] (Дата обращения 23.12.19))

17.Тер-Минасова С.Г. Язык и межкультурная коммуникация. М. Слово. 2000. 624 с. C.40.

18.Hoffmann L. // Band 14.1, (Fachsprachen. Ein internationales Handbuch zur Fachsprachenforshung und Terminologiewissenschaft), 1, Berlin-New York. Walter de Gruyter. 1998. pp. 157-167.

19.Марковина И.Ю. // Вопросы психолингвистики. 2011. Т. 2. № 14. С. 48.

20.Ванюхина М.А. // Профессионально ориентированный перевод: реальность и nерспективы: Сборник научных трудов по материалам 4-ой Международной научнометодической конференции, посвященной 50-летию РУДН. 20-21 мая. 2009 г. М. РУДН. С. 101-109. 
21.Середин А.И. // Молодёжь и наука: Сборник материалов VIII Всероссийской научно-технической конференции студентов, аспирантов и молодых учёных, посвященной 155-летию со дня рождения К.Э. Циолковского 19-27 апреля 2012 г. Министерство образования и науки Российской Федерации. Сибирский федеральный университет. Красноярск. 2012. С.50-53.

22.Гак В.Г., Григорьев Б.Б. Теория и практика перевода. Французский язык. M. URSS. 2019. С. 5-20.

23.Степанов Ю.С. Французская стилистика. М. Высшая школа. 1965. 355 с.

24.Марковина И.Ю., Сорокин Ю.А. Культура и текст. Введение в лакунологию. М. ГЭОТАР-Медиа. 2008, С.4-8.

25.Бархударов Л.С. Язык и перевод. Вопросы общей и частной теории перевода. М. «Международные отношения». 1975. 240 с.

26.Влахов С.И., Флорин С.П. Непереводимое в переводе. М. Р.Валент. 2012. 406 с. (перевод с болгар.).

27. Дупленский Н.К. Письменный перевод. Рекомендации переводчику, заказчику и редактору. М. Р.Валент. 2013. 164 с.

28. Климзо Б.Н. Ремесло технического переводчика. Об английском языке, переводе и переводчиках научно-технической литературы. М. Р. Валент. 2011. 488 с.

29. Corradini D. Handbook of HPLC. CRC Press. Taylor and Francis Group. Boca RatonLondon-New York. 2011. 696 p.

30.Hahn-Deinstrop E. Applied Thin-Layer Chromatography. Best Practice and Avoidance of Mistakes. Weinheim. Wiley-VCH. 2007. Vol. 16. 314 p.
31.Nyiredy Sz. (ed.) Planar Chromatography. A retrospective view for the third millennium. Budapest. Springer Sci. Publ. 2001. 614 p.

32. Raymond P.W. Scott. Liquid chromatography. Column Theory. Chichester-New YorkBrisbane-Toronto-Singapore. John Wiley\&Sons. 1991. 292 p.

33.Berezkin V.G., Zeuuw J.de. Capillary adsorption gas chromatography. Heidelberg, Huethig, $1996.320 \mathrm{p}$.

34. Гиошон Ж., Гийемен К. Количественная газовая хроматография для лабораторных анализов и промышленного контроля (в 2-х частях. ч. II) / под. ред. О.Г. Ларионова. М. Мир. 1991. 375 с.

35.Ванюхина М.А., Берёзкин В.Г. Англорусский и русско-английский словарь по тонкослойной хроматографии (ТСX) (с приложением русско-английского словаря общенаучных конструкций). М. Научный Мир. 2018. $214 \mathrm{c}$.

36. Мисуно Е.А., Баценко И.В., Вдовичев А.В., Игнатова С.А. Письменный перевод специальных текстов. М. Флинта. Наука. 2013. $256 \mathrm{c}$.

37.Ванюхина М.А. // Х Международная научно-практическая конференция молодых ученых «Актуальные проблемы лингвистики и межкультурной коммуникациил. 12 мая 2010. Екатеринбург. УГТУ-УПИ. С. 262-266.

38.Пумпянский А.Л. Введение в практику перевода. М. Наука. 1965. 304 с.

39.Khrebtova S.S., Berezkin V.G. // Journal of Planar Chromatography. 2019. Vol. 32. pp. 355-358. DOI 10.1556/1006.2019.32.5.1.

40.Философия: Энциклопедический словарь / Под ред. А.А. Ивина. М. Гардарики. 2004. $1072 \mathrm{c}$.

\title{
About the using of chromatographic terms and concepts in the English language articles on the topic «Chromatography»
}

\author{
Vanyukhina M.A., Berezkin V.G. \\ A.V.Topchiev Institute of Petrochemical Synthesis, RAS, Moscow
}

Chromatography has been actively developed and applied for the scientific research for over 100 years. The theme of the chromatographic lexics is of great importance for various areas of chemistry, particularly for physical and analytical chemistry. Chromatography is used all over the world in the scientific research, industry, medicine, pharmaceuticals, forensic studies, environmental control etc. The universal language of the intercultural communication, the language of the internationally significant scientific publications, the so-called 'lingua franca', is English. In order to analyze the language picture of chromatographers, the frequency of using of the main chromatographic terms and concepts in Anglophone articles in the area of chromatography has been investigated. The method of calculation has been based on 
the statistical description of the number of terms used in the articles. The statistical data of the global citation database "Web of Science Core Collection" has been analyzed. The paper presents the description of the chromatographic term-system and the core terms. A term-system is an ordered set of terms with particular relations inside the system. Any term-system might serve as a basis for composing a dictionary or for the work of a scientific interpreter. The schematic description of the scientific picture that reflects the core of the linguistic consciousness of a chromatographer as a researcher has been proposed. The sense of a word or a term constructs a semantic net, which might serve as a basis of linguistic consciousness. The scientific picture of a chromatographer is reflected by the chromatographic vocabulary. In the other words, the studied terms and concepts let us virtually "construct" the scientific picture of a chromatographer, which reflects the (mental) lexicon and linguistic consciousness. The core (central) and peripheral scientific lexics permits a chromatographer to operate with all the all the necessary terms and concepts. The description of the vocabulary shows the structure of the science of chromatography. A scientific picture can be represented as a complicated many-layers model. The core of the linguistic consciousness reflects the objective experience of chromatographers, while the peripheral terms refer to more subjective scientific experience. Common language terms such as "mass", "analysis", and "determination" reflect the philosophic facets of a chromatographer's scientific activity. The frequency of using of the main sub-sciences of chromatography GC, LC, TLC - mentioned in the studied articles has been considered by the authors. This research is of interest for translation, as well as for reading and analyzing of scientific literature in the area of chromatography.

Keywords: chromatography, thin-layer chromatography, TLC, gas chromatography, GC, liquid chromatography, LC, chromatographic terms, English language.

\section{References}

1. Tswett M.S. Selected works (Izbrannyye Trudy) / Ed. By Yu.A.Zolotov. M., Nauka, 2013, $679 \mathrm{p}$.

2. Berezkin V.G. Vvedeniye v khromatografiyu, M., Nauchny Mir, 2016, 96 p.

3. Khromatografia: (Osnovnye ponyatia. Terminologia). RAS, Committee on Terminology in the sphere of Fundamental Sciences, Scientific Council on chromatography, Compendium on scientific-normative terminology, Is. 114, M., 1977 pp. 7-12.

4. Berezkin V.G., Journal of Analytical Chemistry. 2001. Vol. 56, No 8, pp. 871.

5. Berezkin V.G., Gavrichev V.S., Kolomiyets L.N., Korolev A.A. et al., Gazovaya khromatografiya $\mathrm{v}$ neftekhimii, M., Nauka, 1975, $271 \mathrm{p}$.

6. PAC, (Nomenclature for chromatography (IUPAC Recommendations)), 1993, 65, pp. 819, 823.

7. Web of Science Core Collection, Available at: [https://apps.webofknowledge.com/ WOS_GeneralSearch_input.do?product=WOS \&search_mode=GeneralSearch \&SID=F6Jeoan 1 DdgmtJlOcGE\&preferencesSaved=] (accessed 20.12.19).

8. Lingvistichesky entsiklopedichesky slovar' / Ed. by V.N.Yartseva, M., Sovetskaya entsiklopedia, 1990, $685 \mathrm{p}$.

9. Ufimtseva N.V., Yazyk v prostranstve rechevykh kul'tur (By the $80^{\text {th }}$ anniversary of E.V.Gol'din), Moscow-Saratov, Nauka obrazovaniya, 2015, pp. 335-342.
10. Zalevskaya A.A., Vvedeniye $v$ psikholingvistiku, M., RGGU, 1999, 382 p.

11. Ufimtseva N.V., Yazyk I metod: Russky yazyk $v$ lingvisticheskikh issledovaniyakh XXI veka, Vol.2, Lingvistichesky analiz nag rani metodologicheskogo sryva / Ed. by D.Shumska, K,Ozga, Krakov, Wydawnictwo Uniwersytetu Jagiellońskiego, 2015, pp. 249-256.

12. Ufimtseva N.V., Balyasnikova O.V., Vestnik VolGu, Series 2, Yazykoznaniye, 2019, Vol. 18, No 1, pp. 6-22.

13. Krongauz M.A. Semantika, M., Akademiya, 2005, $352 \mathrm{p}$.

14. Vasilyev L.M., Voprosy yazykoznanya, 1971, No 3, pp. 105-113.

15. Russky yazyk: Encyclopedia / Ed.by Yu.N.Karaulov, Moscow, Bol'shaya rossiyskaya entsiklopediya, Drofa, 1997, 704 p.

16. Hornby P.A. et al. Bilingualism - Psychological, Social and Educational Implications. New York, San Francisco, London, Academic Press Inc., 1977, 167 p. (in the lectures of T.V. Chernigovskaya, online course, on online platform "Otkrytoye obrazovaniye", 2017, Available

[https://openedu.ru/course/spbu/PSYLING/]

(accessed 23.12.19)

17. Ter-Minasova S.G. Yazyk i mezhkul'turnaya kommunikatsiya, M., Slovo, 2000, $624 \mathrm{p}$.

18. Hoffmann L. Fachsprachen und Gemeinsprache. Handbucher zur Sprach- und Kommunikationswissenschaft. Band 14.1, (Fachspra- 
chen. Ein internationales Handbuch zur Fachsprachenforshung und Terminologiewissenschaft), 1, Berlin - New York, Walter de Gruyter, 1998, pp. 157-167.

19. Markovina I.Yu., Voprosy psikholingvistiki, 2011, Vol. 2, No 14, pp. 48.

20. Vanyukhina M.A., Professionally oriented translation: reality and prospects: Collection book of scientific works on materials of the $4^{\text {th }}$ International scientific-methodological conference, devoted to the $50^{\text {th }}$ Anniversary of PFUR, 20-21 of May, 2009, Moscow, PFUR, pp. 101-109.

21. Seredin A.A., Youth and Science: Collection book of materials of VIII All-Russia scientific-technical conference for students, postgraduates and young scientists, devoted to the $155^{\text {th }}$ anniversary of K.E. Tsiolkovsky, 19-27 of April, 2012, Ministry of Education and Science of the Russian Federation, The Siberian Federal University, Krasnoyarsk, 2012, pp. 50-53.

22. Gak V.G., Grigoriyev B.B. Teoriya i praktika perevoda. Frantsuzsky yazyk, M., URSS, 2019, No 12, pp. 5-20.

23. Stepanov Yu.S. Frantsuzskaya stilistika, M., Vysshaya shkola, 1965, 355 p.

24. Markovina I.Yu., Sorokin Yu.A. Kul'tura i tekst, Vvedeniye v lakunologiyu, M., GEOTAR-Media, 2008, pp. 4-8.

25. Barkhudarov L.S. Yazyk i perevod. Voprosy obshchey I chastnoy teorii perevoda, M., «Mezhdunarodnye otnosheniya», 1975, 240 p.

26. Vlakhov S.I., Florin S.P. Neperevodimoye $\mathrm{v}$ perevode, M., R.Valent, 2012, 406 p.(translated from Bulagarian).

27. Duplensky N.K. Pis'meny perevod. Rekomendacii perevodchiku, zakazchiku i redaktoru, M. R.Valent, 2013, $164 \mathrm{p}$.

28. Klimzo B.N. Remeslo tekhnicheskogo perevodchika. Ob angliyskom yazyke, perevode i perevodchikakh nauchno-tekhnicheskoy literatury, M., R.Valent, 2011, 488 p.

Ванюхина Марина Александровна - к.б.н., ст.н.с., Институт нефтехимического синтеза им. А.В. Топчиева РАН (ИНХС РАН), Россия, Москва

Берёзкин Виктор Григорьевич - д.Х.н., гл.н.с., Институт нефтехимического синтеза им. А.В. Топчиева РАН (ИНХС РАН), Россия, Москва
29. Corradini D. Handbook of HPLC. CRC Press, Taylor and Francis Group, Boca RatonLondon-New York, 2011, 696 p.

30. Hahn-Deinstrop E. Applied Thin-Layer Chromatography. Best Practice and Avoidance of Mistakes. Weinheim, Wiley-VCH, 2007, Vol. 16, 314 p.

31. Nyiredy Sz. (ed.) Planar Chromatography. A retrospective view for the third millennium, Budapest, Springer Sci. Publ., 2001, 614 $p$.

32. Raymond P.W. Scott. Liquid chromatography. Column Theory. Chichester-New YorkBrisbane-Toronto-Singapore, John Wiley\&Sons, 1991, 292 p.

33. Berezkin V.G., Zeuuw J.de. Capillary adsorption gas chromatography. Heidelberg, Huethig, 1996, $320 \mathrm{p}$.

34. Guiochon G., Guillemin C. Quantitative Gas Chromatography for Laboratory Analyses and On-Line Process Control, Amsterdam, Elsevier Science, 1988, Vol. 42, 796 p.

35. Vanyukhina M.A., Berezkin V.G. English-Russian and Russian-English Dictionary on Thin-Layer Chromatography (TLC) (with Application of Russian-English vocabulary of general scientific phrases), Moscow, Scientific World (Nauchny Mir), 2018, 214 p.

36. Misuno E.A., Batsenk I.V., Vdovichev A.V., Ignatova S.A., Pis'menny perevod spetsial'nykh tekstov, M., Flinta, Nauka, 256 p.

37. Vanyukhina M.A., $X^{\text {th }}$ International scientific and practice conference of young scientists "Actual problems of linguistics and cross-cultural communication", 12 of May, 2010, Yekaterinburg, UGTU-UPI, $287 \mathrm{p}$.

38. Pumpyansky A.L. Vvedeniye v praktiku perevoda, M., Nauka, 1965, 304 p.

39. Khrebtova S.S., Berezkin V.G., Journal of Planar Chromatography, 2019, Vol. 32, pp. 355-358, DOI 10.1556/1006.2019.32.5.1.

40. Filosofiya: Encyclopedical dictionary / Ed. by A.A. Ivin, M., Gardariki, 2004, 1072 p.

Vanyukhina Marina A. - a $\mathrm{PhD}$ in ecology (a Candidate of Biological Sciences), a senior researcher, A.V.Topchiev Institute of Petrochemical Synthesis, RAS, Moscow, Russia, E-mail: marava@yandex.ru.

Berezkin Victor G. - Dr. Sci (Chemistry), Professor, a chief investigator, A.V.Topchiev Institute of Petrochemical Synthesis, RAS, Moscow, Russia, E-mail: berezkin@ips.ac.ru. 